\title{
Rhyme Generation in Deaf Students: The Effect of Exposure to Cued Speech
}

\author{
Carol LaSasso \\ Kelly Crain \\ Gallaudet University \\ Jacqueline Leybaert \\ Free University of Brussels
}

This study compares the rhyme-generation ability of deaf participants with severe to profound hearing losses from cued speech (CS) and non-cued speech (NCS) backgrounds with a hearing comparison group for consistent orthographyto-phonology (O-P) rhyming elements, or rimes (e.g., -ail in sail is always pronounced the same), and inconsistent orthography-to-phonology (I-O-P) rhyming elements where the orthographic rime (e.g., -ear) has different pronunciations in words such as bear and rear. Rhyming accuracy was better for O-P target words than for I-O-P target words. The performance of the deaf participants from CS backgrounds, although falling between that of the hearing and the NCS groups, did not differ significantly from that of the hearing group. By contrast, the performance of the NCS group was lower than that of the hearing group. Hearing and CS participants produced more orthographically different responses (e.g., blue-fem), whereas participants from the NCS group produced more responses that are orthographically similar (e.g., blue-true), indicating that the hearing and CS groups rely more on phonology and the NCS group more on spelling to generate rhymes. The results support the use of cued speech for developing phonological abilities of deaf students to promote their reading abilities.

Recently in the educational field there has been a resurgence of emphasis on the development of phonological abilities in hearing students. This phenomenon is related in large part to the substantial body of research correlating phonological awareness (including rhyming) in young hearing children with their subsequent reading achievement (Bradley, 1988; Bradley \& Bryant,

Correspondence should be sent to Carol LaSasso, Department of Audiology and Speech-Language Pathology, Fowler Hall, Gallaudet University, 800 Florida Avenue, Washington, DC 20002 (e-mail: carol.lasasso@ gallaudet.edu).
1983, 1985; Bryant, MacLean, \& Bradley, 1990; Bryant, MacLean, Bradley, \& Crossland, 1990; Ellis \& Large, 1987; Lundberg, Olofsson, \& Wall, 1980; MacLean, Bryant, \& Bradley, 1987). Specifically, phonological awareness tasks (e.g., rhyming) have been shown to have a causal link to subsequent reading achievement in hearing individuals (Bryant, MacLean, \& Bradley, 1990).

In hearing children, the ability to produce and judge rhymes spontaneously is already present between 2 and 3 years of age (Read, 1978; Slobin, 1978), with some individual differences linked to the quality of their oral productions (Webster \& Plante, 1995). Rhyming ability usually emerges spontaneously as a result of natural linguistic development and before any contact with literacy (Morais, Bertelson, Cary, \& Alegria, 1986). The processes used for rhyming seem to change with the acquisition of literacy; whereas preliterate children detect rhymes on the basis of global phonological similarity, first-graders pay more attention to phonemes (CardosoMartins, 1994; Lenel \& Cantor, 1981).

Research related to phonological abilities of deaf students from oral or signing backgrounds (Campbell \& Wright, 1988; Dodd \& Hermelin, 1977; Hanson \& Fowler, 1987; Hanson \& McGarr, 1989; Parasnis, 1996) taken collectively suggests that deaf students with severe to profound hearing losses (i.e., $70 \mathrm{~dB}$ or greater, unaided pure tone average) from oral or signing backgrounds are able to develop phonological abilities, although at a level lower than that of hearing peers. Furthermore, research findings suggest that rhyming judgments of deaf students are strongly influenced by spelling similar- 
ity (Campbell \& Wright, 1988; Hanson \& Fowler, 1987; Hanson \& McGarr, 1989) as well as by articulatory similarity detected by speechreading (Charlier \& Leybaert, 2000; Dodd \& Hermelin, 1977; Hanson \& McGarr, 1989).

Hanson and McGarr (1989) conducted one of the few rhyme-generation tasks involving college-age deaf readers. Participants for that study consisted of 15 congenitally deaf undergraduate students at Gallaudet University, including 8 participants with two deaf parents. No information was provided about communication background prior to coming to Gallaudet; however, it can be presumed that all participants were currently using signs to communicate because Gallaudet University is a bilingual university using American Sign Language (ASL) and English with a communication policy that includes direct visual communication. Participants were given a list of 49 targets and asked to write as many responses as possible that rhymed with the targets. Data analysis consisted of classifying responses as correct or incorrect and dividing correct responses into orthographically similar and orthographically different responses. Incorrect responses were divided into four error categories and tabulated. Those categories included vowel errors (i.e., responses that had the same vowel as the targets but did not rhyme, such as pail-pay), orthographic errors (i.e., responses in which the final spelling pattern was the same as the target, such as bear-dear), speech-related errors (i.e., responses that would look similar to the target on the lips of the speaker, such as one-pant), and unclassified errors. Hanson and McGarr (1989) found that approximately 50\% of deaf participants' responses correctly rhymed with the targets. Of those, there were more orthographically similar responses (e.g., blue-true; $36.5 \%$ of total responses) than orthographically dissimilar responses (e.g., bluefew; $15.7 \%$ of total responses).

Three conclusions emerged from these data. First, as Hanson and McGarr (1989) noted, “orthographically different responses represent the clearest case for rhyme generation because the participant cannot have generated this response based on the orthographic representation of the word" (p. 4). The presence of orthographically dissimilar correct responses thus suggests that deaf participants had developed an ability to identify rhymes independent of orthographic similarity. Consistent with this conclusion was the fact that many of the incorrect responses had the same vowel sound as the target (e.g., pail-pay) and thus can be considered to be approximate rhymes. Second, the high proportion of orthographically similar rhyming responses (e.g., blue-true) indicated that orthographic properties of written words weigh heavily in deaf participants' judgments of rhyme. The error analysis, which shows that half of the incorrect responses had some orthographic similarity to the target (e.g., eight-right, bear-dear), supports this view. Third, these deaf participants also generated rhyme responses on the basis of speech information, that is, visual characteristics of the words on the speakers' lips (see Dodd \& Hermelin, 1977, for a similar view) or the characteristics of their own productions. Some errors (e.g., red-ran) were explained in terms of visibility, and other errors (e.g., phone-phony, blue-balloon) suggested intrusion of segments in the speech of the participants. Finally, despite no available control data, it seems obvious that these deaf participants were not able to generate words at the level expected of hearing peers of the same reading age. If the errors made by deaf individuals in rhyme-generation tasks originate in speech-reading as a partial coding of the phonemic contrasts, it follows that any system that makes visible all the phonological contrasts of a given language should be able to generate phonological representations suitable for rhyme processing. One of these systems using manual clues to disambiguate speechreading is Cued Speech (CS).

Cued Speech (CS), developed by Orin Cornett in 1966 and adapted to more than 56 languages and major dialects (Cornett, 1994), is neither a language nor a manually coded English system that uses ASL signs in English word order. Instead, CS is a mode of communication for visually conveying traditionally spoken languages at the phonemic level (the same linguistic level conveyed via speech to hearing individuals). The American English form of CS uses eight handshapes corresponding to groups of consonants and four hand placements to convey vowels and diphthongs (see Figure 1). The different placements and handshapes combined with nonmanual signals (e.g., mouth shapes) clearly distinguish the 40 or so phonemes of English. For example, the bilabials /p/, $/ \mathrm{b} /$, and $/ \mathrm{m} /$ are visually indistinguishable without voice for hearing individuals or without cues to deaf individuals; however, they are readily differentiated by deaf individuals when cued.

Because CS distinguishes between and among the 


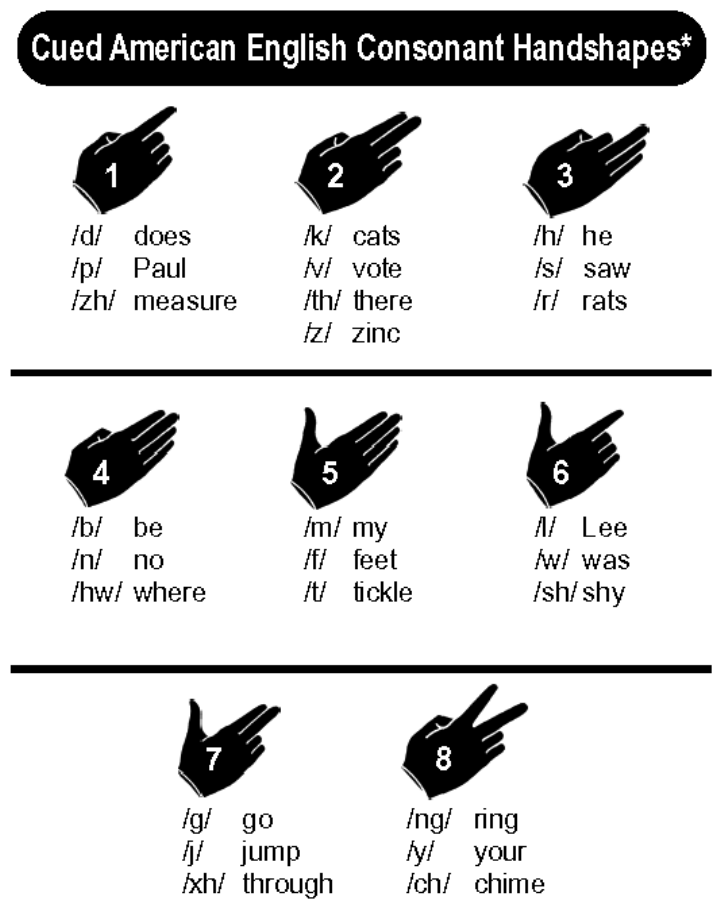

Cued American English Vowel Placements*

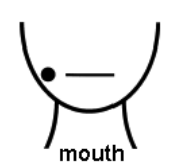

leet see lerf her

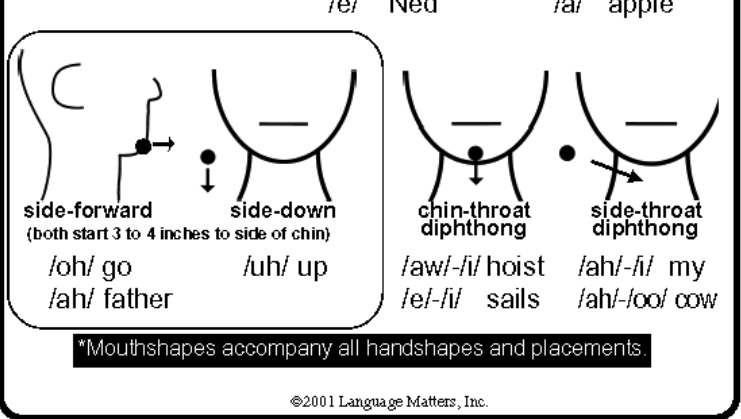

Figure 1 Cued Speech handshapes and placements

40 or so phonemes and resulting syllables, cueing also provides access to morphemes, syntactic structures, and sociolinguistic information related to the language, including rhyming, alliteration, onomatopoeia, accents, and dialects (Cornett \& Daisey, 1992; Kipila \& WilliamsScott, 1990; LaSasso \& Metzger, 1998). By using handshapes, hand placements, and nonmanual signals, CS has been shown to enable deaf individuals to obtain the same linguistic and paralinguistic information visually that hearing individuals obtain auditorially (Alegria, Charlier, \& Mattys, 1999; Hage, Alegria, \& Perier, 1990; Nicholls \& Ling, 1982; Perier, Charlier, Hage, \& Alegria, 1988; Tammasaeng, 1985).

Recent research findings related to CS indicate that deaf individuals from early and intensive CS backgrounds perform more like hearing peers in rhyme judgment tasks than do deaf peers from oral or signing backgrounds (Charlier \& Leybaert, 2000). The same authors asked participants to generate rhyming responses for written French targets that had either consistent orthography-to-phonology (O-P) rimes or inconsistent orthography-to-phonology (I-O-P) rimes. Examples of O-P rhyming elements, or rimes, are -eel and -ote. In all monosyllabic English words, when -eel or -ote appear as rimes, they have consistent pronunciations, meaning a single pronunciation. Examples of rimes with I-O-P in English are -ere and -ood. In English, the rime-ere has a different pronunciation in mere than in mere, and the rime -ood has a different pronunciation in mood than in blood (Ziegler, Stone, \& Jacobs, 1997). The interest in the O-P versus I-O-P variable was the following: If deaf participants were to take a shortcut and generate rhyming responses that have the same orthographic rime as the target word, they would obtain a high level of correct response for O-P targets but a low level of correct response for I-O-P targets.

The results reported by Charlier and Leybaert (2000) showed that early CS users achieved a higher percentage of correct responses than did late CS users, although a lower percentage than the hearing group, and produced many more orthographically dissimilar rhyming responses ( $41.1 \%$ of the total of the responses) than the late CS group $(23.9 \%$ of the total of their responses). Unexpectedly, however, the early CS group showed a consistency effect (12.2\%), which, although lower than that observed for the late CS group (15.5\%), was higher than that displayed by the hearing control group $(0.4 \%)$. This could be interpreted as indicating that orthography is more important in their rhyming abilities than it is for hearing children. A more detailed discussion of this was presented by Charlier and Leybaert (2000). 


\section{Purpose of the Study}

The purpose of this study was to determine whether exposure to Cued Speech is a variable that can explain rhyming abilities of older deaf students by using a methodology similar to that employed by Hanson and McGarr (1989). This study, however, differs from the Hanson and McGarr study in several respects. First, this study compared two groups of deaf participants that varied according to linguistic input related to traditionally spoken English (i.e., cued English or non-cued English). Second, the set of targets used by Hanson and McGarr was split in two sets based on the statistical analysis provided by Ziegler, Stone, and Jacobs (1997). The first set consisted of O-P targets with rhyming elements (or rimes) that have consistent pronunciations in all English monosyllabic words. The second set consisted of targets with I-O-P rhyming elements (or rimes), meaning that not all English words ending with the particular rhyming element necessarily rhyme with the targets. Third, whereas Hanson and McGarr (1989) used a reading comprehension measure that was not designed for deaf students (the Gates-MacGinitie Reading Comprehension Test [1969]) this study employed the 1996 Reading Comprehension Subtest of the 1996 Stanford-9 Achievement Test (SAT-9) that has been specifically modified for use with deaf students. Finally, unlike the Hanson and McGarr (1989) study, this study included a control group consisting of participants with normal hearing who were matched for age and reading level with deaf participants.

This study was designed to provide additional needed insight into phonological abilities of deaf students for researchers and practitioners working with deaf students. Specifically, participants who are using orthographic information to generate rhyme responses could get correct responses for the O-P targets (e.g., true for the target blue); however, using this strategy they would get incorrect responses for the I-O-P targets (e.g., rear for the target bear). They would show a consistency effect (better performance for O-P targets than for I-O-P targets). If, however, participants relied on phonological information to generate rhyme responses, they could produce correct responses both for the O-P and I-O-P targets, thus not showing a consistency effect. In addition this study classified correct responses as either orthographically similar (O-S) or orthographically different (O-D), as did the Hanson and McGarr study (1989). Orthographically different correct rhyming responses (e.g., bear for the target hair) would provide compelling evidence that, counter-intuitively, deaf individuals are able to appreciate rhyme at a phonological level and possibly develop other phonological abilities related to phonological recoding and phonics that are comparable to those of hearing peers and would be helpful for reading development.

\section{Research Questions and Hypotheses}

The following research questions are addressed in this study:

1. Does the level of accuracy on rhyme-generation tasks differ for the following groups of participants who are matched on both age and reading level: participants with normal hearing, deaf participants from CS backgrounds, and deaf participants from NCS backgrounds?

2. Is there an effect of orthography-to-phonology rime consistency, and does this effect interact with groups (hearing, CS, NCS)?

3. Does the nature of correct responses (orthographically similar or dissimilar) differ in the three groups (hearing, CS, NCS)?

4. Is there a relationship between reading ability and rhyme generation?

5. Do the analyses of errors indicate differences between hearing, CS, and NCS participants? How do the results of CS participants and the results of the NCS participants parallel those of the Hanson and McGarr (1989) participants?

It was hypothesized that there would be (a) a significant effect of group with hearing $=\mathrm{CS}>\mathrm{NCS}$ or hearing $>$ CS $>$ NCS and (b) a significant effect of phonologyto-orthography consistency, with O-P items leading to more correct rhyming responses than I-O-P items and a significant interaction between group and the effect of consistency. The NCS group was expected to show a larger effect of consistency than both the hearing and CS groups; the CS group was expected to show a larger effect of consistency than the hearing group. In addition, we expected that although all groups would attempt to generate orthographically different responses, more 
Table 1 Mean percentage of correct responses (standard deviations in brackets) to O-P targets and I-O-P targets, and for total responses for hearing, CS, and NCS participant groups and mean SAT scaled scores

\begin{tabular}{llll}
\hline & Hearing & Deaf cuers & Deaf noncuers \\
\hline O-P targets & $97.50(3.37)$ & $95.44(5.87)$ & $85.64(20.39)$ \\
I-O-P targets & $97.56(2.63)$ & $87.26(10.19)$ & $75.64(21.68)$ \\
Total correct responses & $97.58(3.00)$ & $92.43(6.74)$ & $81.96(9.51)$ \\
Mean SAT scaled scores & $728(30)$ & $725(26)$ & $709(43)$ \\
\hline
\end{tabular}

correct responses that are orthographically different than orthographically similar were expected for the hearing and the CS groups (see Charlier \& Leybaert, 2000); for the NCS group, more O-S than O-D responses were expected (see Hanson \& McGarr, 1989). We also expected a correlation between reading ability and rhyming. More specifically, reading ability should correlate with the ability to generate correct rhymes in response to I-O-P words and to generate orthographically dissimilar rhymes (see Campbell \& Wright, 1988; Leybaert, 1993 for a review). Further, we expected to observe different error patterns; that is, we expected that more errors based on phonological information would be observed in the hearing group and possibly in the deaf CS group, whereas more errors based on orthographic information would be observed in the NCS group. Finally, we expected that the results of the NCS participants would be similar to the results achieved by the college students communicating primarily through sign language tested by Hanson and McGarr (1989) and that the results from the CS participants would differ more.

\section{Method}

Participants

Participants included 20 prelingually deaf participants who reported that they had either severe or profound hearing losses and 10 hearing participants. Unfortunately, we did not have access to the precise decibel level of hearing loss of each of the deaf participants. Of the deaf participants, 10 came from CS backgrounds in which they had early exposure to CS both at home and at school, and 10 came from NCS backgrounds. All deaf participants reside in the Washington, DC, metropolitan area, which includes the District of Columbia and Maryland and Virginia suburbs. None of the deaf par- ticipants reported any additional handicapping conditions. The mean SAT scaled scores of the three groups are reported in Table 1.

Deaf cuers. The 10 CS participants from CS backgrounds ranged in age from 16 to 24 years with a mean age of 19.2 years. Of the 10 participants, 8 were university students, including 3 from Gallaudet University. The other two were high school juniors in the Washington, DC, area. In response to a question asking whether their hearing loss was moderate, severe, or profound, 9 CS participants reported having profound hearing losses, and one reported having a severe hearing loss. Of the 10 participants, there were 6 men and 4 women. In terms of onset of deafness, five participants reported being deaf at birth, four reported becoming deaf prior to the age of 20 months, and one reported becoming deaf prior to the age of 36 months. All CS participants indicated that they had been exposed to CS by one or both parents at home prior to the age of 5 years. Specifically, seven reported being cued to by one or both parents before 3 years of age, two reported being cued to before 4 years, and one participant indicated being cued to at 5 years of age. All participants reported that CS was used as the primary means to convey English conversationally at home and in school during the elementary grades and middle school.

Deaf non-cuers. Deaf participants from NCS backgrounds ranged in age from 17 to 26 years with a mean age of 21.3 years. All participants were students at Gallaudet University who reported that they were currently using signs primarily to communicate conversationally, including ASL and/or sign systems that utilize signs in various degrees of English word order. In response to a question about whether their hearing loss was moderate, severe, or profound, seven of the stu- 
dents reported profound hearing losses, and three reported severe hearing losses. Of the 10 participants, there were 4 men and 6 women. In terms of onset of deafness, six reported being born deaf, two reported becoming deaf prior to the age of 18 months, one reported becoming deaf prior to 30 months, and one reported onset of deafness at 60 months. Five of the NCS participants indicated that they had been exposed to signs by either one or both parents at home prior to the age of 5 years. Of those, four have deaf parents who signed from birth, and one has hearing parents who began to sign before the participant was 3 years old. The other five participants reported that they began signing after the age of 6 years, with two of them not learning to sign until college, and three of them reported that their parents never learned to sign.

Hearing participants. Hearing participants were enrolled in a sign language class at Longwood College in Virginia. They ranged in age from 19 to 21 years with a mean age of 20.1 years.

\section{Stimuli}

For the sake of comparison with the Hanson and McGarr study (1989), we initially planned to use the same set of 49 targets; however, that set contained more O-P words than I-O-P words. Therefore we decided to add five I-O-P targets, thus obtaining a set of 54 targets. ${ }^{1}$ Thirty-one targets have O-P rimes, and the other 23 targets have I-O-P rimes. Targets in the O-P and I-O-P conditions were randomly sequenced in the list of targets (see Appendix A for the complete list of stimuli).

\section{Data Collection}

Most deaf participants in the present study were tested individually; however, for logistics purposes, four of the CS participants were tested in two groups of two students each. Hearing participants were tested together in a classroom setting at Longwood College in Virginia. The rhyming test packet given to participants consisted of five pages. The first page contained the instructions to write as many rhyming words as possible for each target listed in two columns on the following four pages. Participants were instructed that responses could be written more than once for different targets. They were also reminded that words do not need to be spelled the same in order to rhyme. Before taking the test, students had demonstrated to the examiner that they understood the concept of rhyme, including the fact that words do not need to be spelled the same in order to rhyme. There was no time limit; however, the time taken to complete the task for each participant was recorded. All participants completed the task in $30-45 \mathrm{~min}$.

\section{Scoring of Responses}

The scoring procedure consisted of rating responses as being words or nonwords, rating responses judged to be words in terms of whether they rhymed with the targets, classifying rhyming responses as either O-S or O-D to the target, and classifying error responses into the four categories (two of which have subcategories) used by Hanson and McGarr (1989). Ratings were done by two of the authors and a third evaluator who is an experienced teacher of deaf students. Ratings were first done independently then compared until consensus was reached. This was an informal consensus, and no interrater reliability coefficient was computed. Figure 2 depicts the scoring procedure used.

\section{Words Versus Nonwords}

Written responses of participants to targets in the present study were first judged in terms of whether they represented words or nonwords. Most responses were fairly straightforward. If they were correctly spelled English

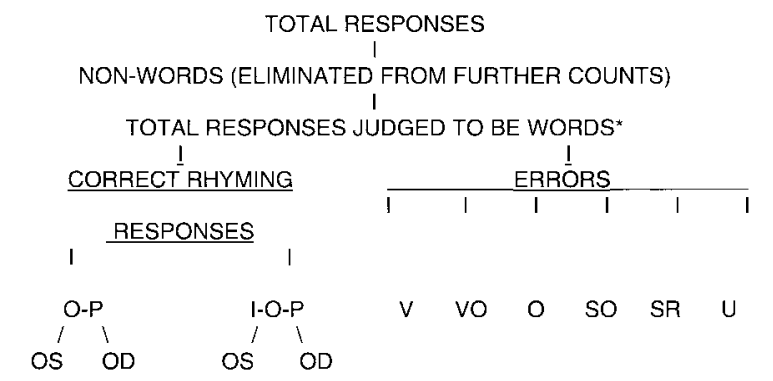

*Including slightly misspelled responses judged capable of being rendered phonically to a response that rhymes with the target

Figure 2 Graphic representation of scoring procedure 
words, they were accepted as words. The Random House College Dictionary (1988) was consulted as a final arbiter of disagreements about whether a response was a word. Examples of responses that were questioned by one or more of the raters, requiring verification as being in the dictionary in order to be included as words were mright, rover, cleave, joules, and pied.

Responses that were less straightforward in terms of being judged to be words or nonwords were responses that were incorrectly spelled but could be pronounced like a correct English word using phonics generalizations. For example, the response moure could be considered to be a misspelling of more. After some discussion it was decided that because this study relates to students' rhyming abilities, there seemed to be some merit in counting incorrectly spelled responses as correct if they were phonically rendered versions of words that rhymed with the target word. Using this decision rule, the response moure was considered to be a misspelling of more, which rhymes with the target pour; thus it was counted as a correct response. An example of a response that was not counted as a misspelled word in the present study is nack, which could be a misspelling of knack. Because knack does not rhyme with the target tax, nack was counted not as a correct response but as a nonword.

The most difficult word-versus-nonword decision faced by raters related to single graphemes (letters of the alphabet) such as $c$ or $b$ provided by one participant as a rhyming response for the target key. Because these graphemes have letter names produced with a vowel sound (e.g., the grapheme $b$ is pronounced bee, and the grapheme $c$ is pronounced see) and meaningfully represent the name of a particular grapheme, we counted these graphemes as spoken words for this study. It should be noted that only seven of the total responses were single graphemes.

\section{Rhyming Versus Nonrhyming Responses}

After responses were judged to be words or nonwords, the responses that had been judged to be words were rated in terms of whether they rhymed with the target. Nonrhyming responses were counted as errors. Most decisions about whether responses rhymed with the target were fairly straightforward, with raters being in complete agreement. Two types of responses for which rhyming decisions were less straightforward, requiring discussion among raters in order to reach consensus, were (a) multisyllabic responses in which the final syllable to be judged for its rhyming characteristic was unstressed (e.g., city) and (b) responses with multiple pronunciations, such as present, which is pronounced differently when used to refer to a noun (i.e., gift) than when used as a verb (i.e., give).

The first type of response for which rhyming decisions were not always straightforward was multisyllabic responses in which the final syllable being judged for its rhyming characteristic was an unstressed syllable (e.g., city and pity). Technically, because the $y$ in words such as cit- $y$ and $p i t-y$ is not stressed, it is transcribed as a short $i / \mathrm{i} /$ as in cit-ih in accordance with the International Phonetic Alphabet (IPA, 1996) and is thus transliterated as /i/ when cued. Therefore such responses were counted as incorrect in this study when provided as rhyming responses for key words with a long $e$ rime (e.g., $k e y$ ). It should be noted that only one response fell into this category. We considered this technicality; however, we considered the change in pronunciation to be minimal and thus determined the $y$ in the unstressed syllable to be merely an allophone of the vowel that could be judged for its rhyming relationship to targets.

The second type of response for which rhyming decisions were less than straightforward was responses that had more than one pronunciation. For example, read can be pronounced with either a long or short $e$, depending on whether the word is present or past tense. In these situations, participants were given the benefit of the doubt for purposes of rhyming decisions.

\section{Categories of Correct Rhyme Responses}

Responses that were judged to be correct rhyming responses for targets were then classified as being either $\mathrm{O}-\mathrm{S}$ to the target (e.g., O-P target blue-glue; I-O-P target school-cool) or O-D to the target (e.g., O-P target blue-few; I-O-P target bear-fare).

\section{Categories of Errors}

Incorrect rhyme responses were classified as errors. Errors were then classified into one of four categories, two of which had subcategories, resulting in a total of six er- 
ror categories that had been employed by Hanson and McGarr (1989). First, using the same procedure as Hanson and McGarr in the same specified sequence, incorrect responses in this study were examined to determine whether the vowel portion of the response, regardless of other portions of the response, was the same as the vowel portion of the target. Responses that contained the same vowel sounds were classified in terms of whether they were vowels orthographically similar (VO) to the target or orthographically dissimilar (V). Responses that were not classified as vowel responses were examined for orthographic (O) similarity. Specifically, they were examined to determine whether the final portion of the response carrying the rime was identical to that in the target. Examples of responses with $(\mathrm{O})$ similarity are eight-meigh, dear-mear, or one-throne. Responses that were not classified as $\mathrm{V}, \mathrm{VO}$, or $\mathrm{O}$ were evaluated to determine whether they had some but not complete orthographic similarity (SO) to the target. Examples of SO responses are feel-fell, or bear-beer. Responses that were not classified as $\mathrm{V}, \mathrm{VO}, \mathrm{O}$, or $\mathrm{SO}$ were judged in terms of whether or not they were speech related (SR), meaning that they looked similar to the target on the mouth of the speaker. Examples of SR responses from the Hanson and McGarr study (1989) are one-pant and box-mat. Examples of SR responses from this study are door-tour, bear-peer, and pail-bell. Finally, responses that were not classified as $\mathrm{V}, \mathrm{VO}, \mathrm{S}$, or SR errors were classified as unclassifiable (U). Examples of unclassifiable responses in this study are feel-kill and hair-rear. To summarize, at the completion of the analysis all errors were classified into one of the following six categories: vowel $(\mathrm{V})$, vowel with orthographic similarity (VO), orthographic (O), some orthography (SO), speech related (SR), or unclassified (U).

\section{Results}

Questions 1 and 2

The first two questions were, Does the level of accuracy differ for hearing, CS, and NCS matched for reading level? and Is there an I-O-P effect of orthography-tophonology inconsistency and if so, does this effect interact with groups?

Because this experiment is concerned with rhyme generation as a function of a variable $(\mathrm{O}-\mathrm{P})$ associated with reading ability, it is important to verify that the three groups did not differ regarding their measured reading level. Table 1 contains the mean percentage of correct responses to $\mathrm{O}-\mathrm{P}$ targets and correct responses to I-O-P targets for the different participant groups (hearing, CS, NCS) together with their SAT scores. A one-way ANOVA with group (three levels: hearing, CS, and NCS) performed on the SAT scores revealed no significant effect of group, $F(2,27)=0.84 ; p>.10$. Our three groups could thus be considered as equivalent regarding their measured reading level.

The mean percentages of correct rhyming responses for O-P targets and I-O-P targets were analyzed with a mixed ANOVA with group (three levels: hearing, CS, and NCS) as the between-participants factor and orthography-to-phonology consistency (two levels: consistent, inconsistent) as the within-participants factor. ${ }^{2}$ The ANOVA was run on the mean percentage of correct responses by participant. The ANOVA yielded significant effects of O-P consistency, $F(1,27)=9.48 ; p$ $<.01$, and of group, $F(2,27)=4.98 ; p<.05$. The interaction between group and $\mathrm{O}-\mathrm{P}$ consistency failed to reach significance, $F(2,27)=2.45 ; p=.11$. A post-hoc Tukey HSD test revealed that hearing participants differed significantly from NCS participants $(p<.05)$ but not from CS participants and that CS participants did not differ from NCS participants $(p=.14)$.

The mean percentage of correct responses by target was also computed for each group of participants. A mixed ANOVA with O-P consistency (two levels: consistent, inconsistent) as the between factor and group of participants (three levels: CS, NCS, hearing) as the within factor was run on these data. The analysis yielded significant effects of group, $F(1,52)=11.22 ; p<.005$, and O-P consistency, $F(1,52)=5.25 ; p<.05$. The group by O-P consistency was not significant, $F<1$.

Question 3

The third question was, Does the proportion of orthographically similar and dissimilar responses differ in the three groups?

Table 2, showing mean percentages of responses classified as correct and incorrect rhyming responses for hearing, CS, and NCS groups, indicates that the major- 
Table 2 Mean percentage classified as correct and incorrect rhyming responses for hearing, CS, and NCS groups (standard deviations in brackets)

\begin{tabular}{lccc}
\hline & Hearing $(\%)$ & Deaf CS users $(\%)$ & Deaf non-CS users $(\%)$ \\
\hline Correct responses & & & \\
Orthographically dissimilar & $62.50(5.13)$ & $56.90(9.52)$ & $33.70(20.47)$ \\
Orthographically similar & $34.80(4.26)$ & $35.60(5.10)$ & $48.20(12.98)$ \\
Incorrect responses & $2.40(2.91)$ & $7.60(6.59)$ & $18.20(11.38)$ \\
Total & 100.0 & 100.0 & 100.0 \\
\hline
\end{tabular}

ity of the responses generated by the three groups in this study did correctly rhyme with the target $(97.5 \%$ for hearing, $92.4 \%$ for CS, and $82.0 \%$ for NCS participants). In the hearing and the CS groups, correct orthographically dissimilar rhymes were produced more often than were orthographically similar rhymes; the NCS group produced more orthographically similar than orthographically dissimilar rhymes. For the sake of comparison with Hanson and McGarr's (1989) results, we adopted the same presentation of the data.

The percentages of correct orthographically similar responses were analyzed with a one-way ANOVA, with group (hearing, CS, NCS) as the between-subjects factor. The group factor was highly significant, $F(2,27)=$ $7.97 ; p<.005$. A post-hoc Tukey HSD test revealed that the NCS group produced significantly more orthographically similar responses than either the CS group or the hearing group, which did not differ from each other. The percentages of correct orthographically dissimilar responses were also analyzed with a one-way ANOVA. The group factor was again highly significant, $F(2,27)=13.06 ; p<.001$. A post-hoc Tukey test showed that the NCS group produced significantly fewer orthographically dissimilar responses $(p<.005)$ than either the CS group or the hearing group, which did not differ from each other.

\section{Question 4}

Next we asked the question, Is there a relationship between reading ability and rhyming accuracy?

In an effort to determine a relationship between reading ability and rhyming ability, Pearson's $r$ correlation coefficients were computed between the different measures of rhyme generation previously used and the SAT scores, including both hearing and deaf partici- pants $(N=30)$. The reading score explained a significant variance of the proportion of correct responses for I-OP rhymes $(r=0.50 ; p=.005$, two-tailed) but not of the proportion of correct responses to O-P rhymes $(r=0.21$; $p>.10)$ : Indeed, most of the participants reached more than $95 \%$ of correct responses in this condition. It is interesting that SAT scores correlated significantly and positively with the proportion of correct responses that were orthographically dissimilar $(r=0.54 ; p=.002$, two-tailed) and also significantly but negatively with the proportion of correct responses that were orthographically similar $(r=-0.50 ; p=.005$, two-tailed). In sum participants with higher SAT scores were more able than participants with lower SAT scores to generate rhymes to I-O-P targets and to generate rhymes that were orthographically dissimilar from the targets. It is interesting that these correlations held for the 20 deaf participants alone: SAT and O-P correct responses: .15; SAT and I-O-P correct responses: $.50(p<.05)$; SAT and orthographically similar responses: $-.50(p<.05)$; SAT and orthographically dissimilar responses: .53 $(p<.05)$.

\section{Question 5}

Finally we asked, Does the analysis of errors indicate differences between hearing, CS, and NCS participants? and How do the results of the present study compare with those of Hanson and McGarr (1989)?

Table 3 compares participant groups (CS, NCS, hearing) in terms of total responses, total correct rhymes, total errors, total nonwords, and proportions of errors in each of the six error categories. For the sake of comparison, corresponding data from the Hanson and McGarr (1989) study have also been included (see Appendix B for a detailed account of the errors).

Vowel errors predominate in all three groups, as they 
Table 3 Summary data related to age, reading level, correct rhymes, errors, and nonwords for participant groups in this study and in the Hanson and McGarr (1989) study

\begin{tabular}{|c|c|c|c|c|}
\hline & $\begin{array}{l}\text { Deaf CS } \\
(n=10)\end{array}$ & $\begin{array}{l}\text { Deaf non-CS } \\
(n=10)\end{array}$ & $\begin{array}{l}\text { Hearing } \\
(N=10)\end{array}$ & $\begin{array}{l}\text { Hanson and McGarr } \\
(1989)(n=15) \\
\end{array}$ \\
\hline Mean age & 19.2 years & 21.3 years & 20.1 years & $\begin{array}{l}\text { Ages not reported; } \\
\text { Gallaudet undergrad } \\
\text { students (typically } \\
18-27 \text { yrs.) }\end{array}$ \\
\hline Mean measured reading level(grade level) ${ }^{\mathrm{a}}$ & Post-high school & Grade 12.8 & Post-high school & Grade 10.1 \\
\hline Total attempted responses ${ }^{\mathrm{b}}$ and means & $2,596(260)$ & $1,345(135)$ & $2,501(250)$ & $1,199(80)$ \\
\hline Total correct rhymes and means & $2,427(243)$ & $1,197(120)$ & $2,443(244)$ & $626(42)$ \\
\hline Total errors ${ }^{\mathrm{c}}$ & $169(6 \%)$ & $148(11 \%)$ & $58(2 \%)$ & $573(48 \%)$ \\
\hline Vowel errors $^{\mathrm{d}}$ & $23(14 \%)$ & $20(14 \%)$ & $21(36 \%)$ & $83(15 \%)$ \\
\hline Vowel orthographic errors & $47(27 \%)$ & $46(31 \%)$ & $13(22 \%)$ & $94(16 \%)$ \\
\hline Orthographic errors & $57(34 \%)$ & $40(27 \%)$ & $3(5 \%)$ & $76(13 \%)$ \\
\hline Some orthographic errors & $24(14 \%)$ & $30(20 \%)$ & $9(16 \%)$ & $136(24 \%)$ \\
\hline Speech-related errors & $5(3 \%)$ & $1(.6 \%)$ & $5(9 \%)$ & $81(14 \%)$ \\
\hline Unclassified errors & $13(8 \%)$ & $11(7 \%)$ & $7(12 \%)$ & $103(18 \%)$ \\
\hline Nonwords $^{\mathrm{e}}$ & $10(.04 \%)$ & $4(.03 \%)$ & $2(.01 \%)$ & $8(1 \%)$ \\
\hline
\end{tabular}

a The SAT-9 (1996, Advanced II Reading Comprehension subtest) was used to determine reading levels of the 30 participants in the present study. Hanson and McGarr (1989) reported reading levels for only 8 of their 15 participants. They used the Gates-MacGinitie Reading Tests (1969, Survey F, Form 2). Scores reported here are grade-level equivalents derived from scaled scores on the SAT-9 and standard scores on the Gates-MacGinitie test.

${ }^{\mathrm{b}}$ Based on 49 targets in the Hanson-McGarr (1989) study and 54 targets in this study.

${ }^{c}$ Percentages are of the total responses (minus nonwords).

${ }^{\mathrm{d}}$ Percentages for the error categories are based on incorrect responses in a category.

${ }^{\mathrm{e}}$ Percentages are based on the number of total responses.

did in the Hanson and McGarr (1989) study. The total combined vowel $(\mathrm{V})$ errors + vowel orthographic $(\mathrm{VO}) \mathrm{er}-$ rors represented $58 \%$ of the errors of the hearing group, $42 \%$ of the errors of the CS group, and $45 \%$ of the errors of the NCS group versus $31 \%$ in the Hanson and McGarr (1989) study. It is interesting that the percentages of $\operatorname{vowel}(\mathrm{V})$ errors for CS and NCS deaf participants in the present study (14\% in both groups) were basically the same as those in the Hanson and McGarr (1989) study (14.5\%) but considerably lower than the $36 \%$ vowel (V) errors for hearing participants in this study. These errors represented approximate rhyming responses.

Orthography-related responses accounted for a much larger proportion of error responses in the deaf groups than in the hearing group. Specifically, of total errors, $75 \%$ for CS, $78 \%$ for NCS, versus $43 \%$ for hearing are orthographically related compared with $52 \%$ of total errors in the Hanson and McGarr (1989) study.

Finally, to try to understand the large discrepancy in the error rates in this study $(6 \%)$ compared with that in the Hanson and McGarr (1989) study (48\%), we com- pared the three groups (CS, NCS, hearing) in this study with the group in the Hanson and McGarr (1989) study in terms of proportions of nonword responses; total attempted, correct, and incorrect responses; numbers of multisyllabic responses; numbers of responses classified as proper nouns, exclamations, onomatopoeia, nonEnglish words, and abbreviations that we accepted in this study; and reading levels of participants.

The proportion of nonword responses (see Table 3 ) to total attempted responses was $.03 \%$ ( $\mathrm{CS}, .04 \%$; NCS, $.03 \%$; hearing, . $01 \%$ ) compared with $1.0 \%$ in the Hanson and McGarr (1989) study.

More important differences were found between mean attempted responses in the two studies; that is, the overall mean of 215 (CS, 259; NCS, 134; hearing, 250) attempted responses in this study compares with 80 in the Hanson and McGarr (1989) study. Hearing and CS participants in this study produced more than three times the number of responses as the Hanson and McGarr participants, and NCS participants produced more than $50 \%$ more responses than the Hanson and 
McGarr participants. Differences were also found in the proportion of correct rhymes to total responses (total, 94\%; CS, 93\%; NCS, 89\%; hearing, 98\%) compared with $52 \%$ in the Hanson and McGarr study. The mean number of correct rhymes per participant in this study was 212 (CS, 242; NCS, 119; hearing, 244) compared with 42 in the Hanson-McGarr study.

Further analyses of response characteristics in the two studies produced some interesting differences related to proportions of multisyllabic responses and responses in the categories of non-American English words (e.g., quiche), proper nouns, onomatopoeia, exclamations, abbreviated forms of words (e.g., dorm for dormitory), and misspellings.

First, the proportion of multisyllabic responses in this study differs from that in the Hanson and McGarr (1989) study. Specifically, in this study, of the 6,067 correct responses (CS, 2,427; NCS, 1,197; hearing, 2,443), 119 (CS, 39; NCS, 22; hearing, 57) were multisyllabic, which represents slightly less than $2 \%$ (CS, $1.6 \%$; NCS, $1.8 \%$; hearing, $2.3 \%$ ). The mean was 3.9 multisyllabic responses per participant (CS, 3.9; NCS, 2.2; hearing, 5.8) and a mean of .45 multisyllabic responses (CS, .70; NCS, .40; hearing, 1.1) for each of the 54 targets. In the Hanson and McGarr study, of the 626 correct responses only $4(6 \%)$ were multisyllabic, with a mean of .26 multisyllabic responses per participant and a mean of .8 multisyllabic responses per target $(n=49)$. Of the 375 incorrect responses in this study, 23 were multisyllabic, with an overall mean of .76 multisyllabic responses per participant (CS, .6; NCS, 1.2; hearing, .4) and a mean of.43 incorrect multisyllabic responses for each of the 54 targets. This compares with 38 multisyllabic responses of 573 incorrect responses in the Hanson and McGarr study with a mean response of 2.5 incorrect multisyllabic responses per participant in that study and .78 multisyllabic responses for each of the 49 targets.

Second, differences were found between participant groups in this study and the Hanson and McGarr (1989) group related to non-American English words (e.g., lieu, beaucoup), proper nouns, (e.g., Fred, Maine), exclamations (e.g., hey, yoo-hoo, whoa), shortened or abbreviated forms of words (e.g., dorm for dormitory), and onomatopoeia (i.e., sounds such as moo or tick-tock that imitate sounds). See Table 4 for total numbers of responses
Table 4 Comparison of responses in this study and the Hanson and McGarr (1989) study

\begin{tabular}{lll}
\hline & This study & $\begin{array}{l}\text { Hanson-McGarr } \\
(1989)\end{array}$ \\
\hline Non-American English & 17 & 0 \\
Proper nouns & 57 & 8 \\
Shortened forms & 21 & 4 \\
Exclamations & 28 & 2 \\
Onomatopoeia & 7 & 1 \\
\hline
\end{tabular}

in the different categories for the different participant groups compared with Hanson and McGarr's data (the complete list of these responses for the three groups is available from the authors).

Finally, differences related to misspelled responses between this study and the Hanson and McGarr (1989) study were found. In this study, 31 misspelled responses were counted as correct rhyming responses, using the decision rule that if a misspelled response could be pronounced like a correctly spelled response that rhymed with the target, it would be counted as correct despite its misspelling. Using this rule, the response dail to the target pail would have been counted as a misspelling of dale and thus a correct rhyming response. Using the same decision rule, however, if dail had been given as a response to the target thief, it would have been counted as a nonword in the present study. The number of misspelled responses was 1 for the CS group, 6 for the NCS group, and 0 for the hearing group. It is interesting that no mention of misspellings is made by Hanson and McGarr (1989), and none of the list of total responses in that study's appendix contained misspellings. Hanson and McGarr (1989) indicate that they gave participants the benefit of the doubt when there was more than one pronunciation of written responses. For example, tear as a response could be pronounced with either a long $e$ or a long $a$ sound. When that response was produced as a rhyming response to bear, the response was counted as correct.

\section{Discussion}

The findings of this study provide evidence regarding our five hypotheses. The first hypothesis was that deaf participants from CS backgrounds would achieve a higher level of correct rhyme production than would 
participants from NCS backgrounds and comparable to that of hearing peers. This prediction was partially confirmed by our data, which showed no difference between the hearing and the CS groups and the NCS group scoring lower than the hearing group. The lower accuracy of the NCS participants could not be ascribed to their reading levels because the NCS group was indistinguishable from the hearing group in SAT scores. A fully specified phonological input appears to be critical in the development of deaf participants' rhyming abilities, independently of the modality of input (Charlier \& Leybaert, 2000); however, it must be noticed that no significant difference was obtained between the CS and the NCS groups, and the raw level of performance of the CS group, although not significantly different from that of the hearing group, fell in between performance levels of the hearing and the NCS groups.

The second hypothesis was that there would be an effect of O-P consistency, which would be larger in the NCS deaf participants than in either the hearing or CS groups. This prediction was not supported statistically; that is, although there was a significant effect of O-P consistency there was no significant interaction between this effect and group in either the analysis by participants or the analysis by items. The raw percentage of correct responses for O-P and I-O-P words indicates that the two groups of deaf participants were more influenced by word spelling in their attempts to generate rhymes than the hearing participants were. This point will be discussed in this article after considering the nature of the correct responses.

The third hypothesis was that although all three groups would attempt to generate orthographically different responses, the rate of correct responses that are orthographically different would be higher in the hearing and CS groups than in the NCS group. The data confirm this hypothesis. As expected, the hearing and CS groups showed significantly more correct responses that are orthographically different than did the NCS group, whereas the NCS group showed more orthographically similar responses than either the hearing or CS group. There seems to be a contradiction in the data discussed up to now. On the one hand, the rate of orthographically similar and dissimilar correct responses indicates that compared with the hearing and CS groups, our NCS participants used more of a "shortcut" strategy in which they generated words that contain the same orthographic rime as the target. On the other hand, the absence of interaction between the effect of O-P consistency and group indicates that both the CS and NCS participants generate rhymes more easily for O-P targets than for I-O-P targets. How can these two findings be reconciled? It could be that deaf participants from the CS group used the phonological information to produce rhymes but that in some cases they have stored inappropriate pronunciations in their lexicon, derived from the word spelling. For example, they could pronounce blood like should and incorrectly generate responses such as blood, flood to the target should, which were scored as incorrect. The results thus point to the complexity of rhyme generation by deaf students. Cued speech aids phonological awareness, but some dependence on orthography remains. Charlier and Leybaert (2000) found similar results. It must be remembered that even if the students from the CS group had been exposed to CS early (before the age of 5 years), they did not benefit from incidental learning of the phonological forms of words to the same degree as did most of the hearing children. Indeed, their learning of phonological forms was dependent on input from considerably fewer people cueing to them. Therefore it is not surprising that they relied more on word reading to develop their knowledge of the phonological forms and of rhyming words.

Our data also confirm the fourth hypothesis, that there is a relationship between deaf people's rhymegeneration ability and their reading ability (Campbell \& Wright, 1988; Hanson \& Fowler, 1987; see Leybaert, 1993 for a review). Specifically, the readers with higher SAT scores were better at generating responses to I-O$\mathrm{P}$ targets and better at generating correct rhymes that were orthographically dissimilar. Whether phonological sensitivity promotes reading or the relationship is the opposite could not be determined from this study's data. Longitudinal data measuring rhyme awareness before learning to read and the subsequent development of reading are needed to disentangle these two possibilities.

Our fifth research question was whether error analyses would indicate differences between the three groups and whether the performance of NCS participants in our study would be more similar to that of the participants in the Hanson and McGarr (1989) study 
than that of the CS or hearing participants in this study. The error analysis indicates that the hearing group made more vowel errors and fewer orthography-related errors than the two deaf groups.

However, other aspects of the data revealed differences between our three groups and are worthcomparing with Hanson and McGarr's (1989) data. One interesting finding relates to the number of attempted responses between participants in the two studies. Whereas the mean number of attempted responses in the Hanson and McGarr study was 80 , the mean number of attempted responses in our study was 135 for the NCS group, 260 for the CS group, and 202 for the hearing group. As expected, the results of our NCS participants were more similar to the results achieved by the college students tested by Hanson and McGarr, and the results from the CS participants differed more greatly. Hearing and CS participants produced twice the number of responses than the NCS participants did. This range of responses could give us a hint about the strength of the representation of rhyme; that is, this finding supports the idea that NCS participants compared with CS and hearing participants have a less stable understanding of rhyme and that rhyme generation is a more difficult exercise for them. It also indicates that the NCS participants in this study could be more skilled at rhyming than Hanson and McGarr's participants. Compared with the $52 \%$ correct rhyming responses reported by Hanson and McGarr (1989) for deaf signing participants, the level of accuracy of our deaf participants from NCS backgrounds was surprisingly high (94\%) despite our control for age and educational setting at the time of data collection. Specifically, deaf participants from NCS backgrounds in our study, like the deaf participants in the Hanson and McGarr study, were all Gallaudet students of comparable age. It is interesting that our NCS participants differed from those in the Hanson and McGarr study more on the rate of correct orthographically dissimilar responses $(33.8 \%$ versus $15.7 \%$ ) than on the rate of correct orthographically similar responses $(48.2 \%$ versus $36.5 \%$ ). The number of attempted responses cannot explain this difference. In Hanson and McGarr's study, the mean number of attempted responses was 79.93 (1,199 responses produced by 15 participants). In our study, this mean reached 134.4 responses. It is thus not the case that our deaf participants from NCS backgrounds reached a higher accuracy level because they wrote fewer responses for each stimulus.

There are at least five possible explanations for these differences. First, our participants were tested individually or in small groups of participants, whereas the testing situation used by Hanson and McGarr (1989) was not described. Individual testing might reduce participants' peer pressure as well as time pressure and could thus be a situation more suitable for testing deaf participants' rhyming abilities.

Second, our NCS participants might have better reading abilities than those in the Hanson and McGarr study. Hanson and McGarr reported standard scores for 8 of the 15 participants on the 1960 Gates-MacGinitie Reading Comprehension Test that reflected a gradelevel equivalent of 10 th grade. We obtained scaled scores that reflected grade-level equivalents of post-12th grade. Caution should be exercised in assuming that deaf students will have the same "reading levels" or "grade-level equivalents" on both the Gates-MacGinitie Reading Comprehension Test and the 1996 SAT. LaSasso (1987) discusses the inappropriateness of ascribing reading levels or grade-level equivalents to deaf students from tests designed for hearing students.

Third, our NCS participants could be more linguistically sophisticated than the participants in the Hanson and McGarr (1989) study. Indeed, our NCS participants produced more responses and more responses that were abbreviations, proper nouns, onomatopoeia, words borrowed from other languages, and exclamations, which arguably reflect a greater linguistic sophistication.

Fourth, approximately half of our participants reported having early and ongoing exposure to signs whereas the other half reported later exposure or less consistent exposure to signs. In the Hanson and McGarr (1989) study no mention was made about the participants' communication history.

Finally, the differences could be related to speech intelligibility. Hanson and McGarr (1989) found that better speech intelligibility was associated with more correct rhymes generated. We did not collect speech intelligibility data and thus are unable to discuss any possible relationships. In any case, the results of our deaf participants from NCS backgrounds are striking: They show 
that achieving a high level of accuracy in phonological ability is not impossible for deaf people from NCS backgrounds.

In conclusion, our study demonstrates the degree to which deaf participants from different communication backgrounds can generate rhymes. The relationship between measured reading ability and rhyming accuracy supports the view that phonological skills are important for deaf people to achieve high measured reading levels. The causal model linking phonological awareness to reading achievement that has been strongly emphasized for hearing children (Bryant, McLean, \& Bradley, 1990) seems valid for deaf youngsters as well. In support of this hypothesis, Harris and Beech (1995) showed that the reading progress made by deaf children during their first year of reading instruction was predicted by their performance 10 months earlier on a version of Bradley and Bryant's (1983) “odd-man-out” phonemic sensitivity test as well as by their oral skills. In addition, our data demonstrate that experience with CS can enhance rhyming ability. Specifically, the performance of the deaf participants from CS backgrounds, although falling between that of the hearing and the NCS groups, did not differ significantly from that of the hearing participants. It is likely that the development of good phonological representations through experience with CS would facilitate the acquisition of reading and spelling in an alphabetic writing system in traditionally spoken languages such as English; however, longitudinal studies, such as that of Harris and Beech (1995) measuring the predictive power of level of rhyme awareness before learning to read and the subsequent development of reading, are needed to establish this point.

\section{Appendix A: List of Targets in O-P and I-O-P Conditions}

\begin{tabular}{llll} 
O-P Targets & & I-O-P Targets \\
\hline blue & tie & school & won \\
cry & rain & bear & key \\
pail & hair & tea & pour \\
steal & thief & shoe & should \\
late & rule & please & said \\
peace & vote & phone & new \\
door & beach & one & eight \\
box & feel & cough & lost \\
shirt & beef & care & warm \\
off & lane & own & great \\
speech & weigh & wood & here \\
hurt & boat & love & \\
sale & day & & \\
red & socks & & \\
tax & tacks & & \\
see & & & \\
\hline
\end{tabular}

Appendix B: Errors in This Study Categorized According to Hanson \& McGarr's Error Types

\begin{tabular}{lcc} 
Targets & NCS & CS \\
\hline beach & 1 bench $(\mathrm{SO})$ & 19 ditch $(\mathrm{SO})$ \\
& 2 niche $(\mathrm{SO})$ & leash $(\mathrm{VO})$ \\
& 20 quiche $(\mathrm{V})$ \\
bear & 7 near $(\mathrm{O})$ & 11 fear $(\mathrm{O})$ \\
& clear $(\mathrm{O})$ \\
& dear $(\mathrm{O})$ \\
& 16 rear $(\mathrm{O})$ \\
& fear $(\mathrm{O})$ \\
& peer $(\mathrm{SO})$ \\
& 19 near $(\mathrm{O})$ \\
& dear $(\mathrm{O})$ \\
& ear $(\mathrm{O})$ \\
& fear $(\mathrm{O})$ \\
& gear $(\mathrm{O})$
\end{tabular}




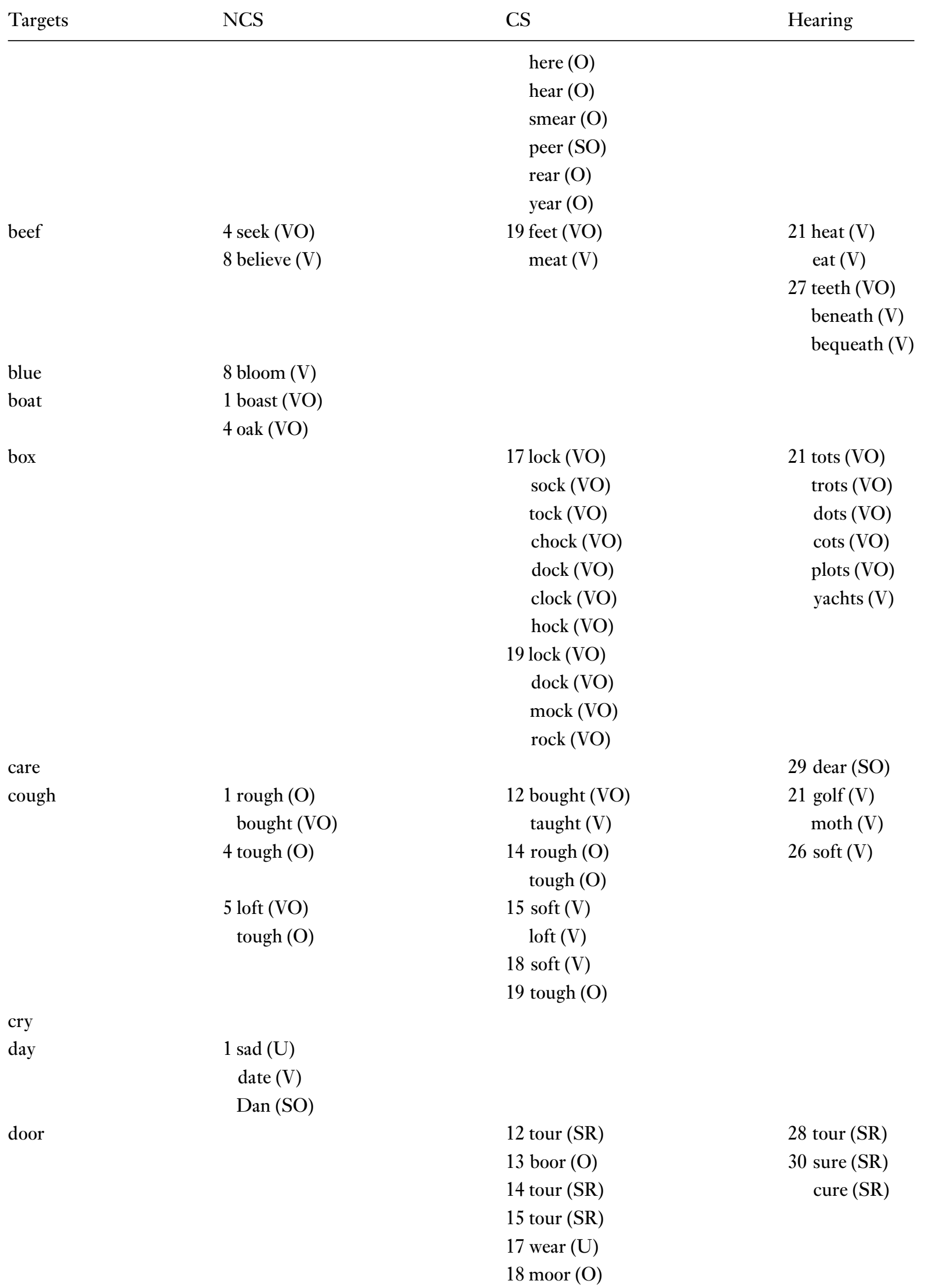




\begin{tabular}{|c|c|c|c|}
\hline Targets & NCS & CS & Hearing \\
\hline \multirow[t]{2}{*}{ eight } & 1 either (U) & & \\
\hline & 5 cake $(\mathrm{V})$ & & \\
\hline \multirow[t]{2}{*}{ feel } & & 19 fail (SO) & 23 kill (U) \\
\hline & & & 26 will (U) \\
\hline \multirow[t]{8}{*}{ great } & 3 cat $(\mathrm{SO})$ & 12 treat $(\mathrm{O})$ & \\
\hline & 5 treat $(\mathrm{O})$ & heart (SO) & \\
\hline & & 14 meat $(\mathrm{O})$ & \\
\hline & & feet (SO) & \\
\hline & & feat $(O)$ & \\
\hline & & 19 bright (U) & \\
\hline & & fray $(\mathrm{V})$ & \\
\hline & & gray (V) & \\
\hline hair & 6 hail (VO) & 18 rear $(\mathrm{U})$ & \\
\hline \multirow[t]{3}{*}{ here } & 1 heir (SO) & & \\
\hline & where $(\mathrm{O})$ & & \\
\hline & 3 deaf $(\mathrm{U})$ & & \\
\hline \multirow[t]{4}{*}{ hurt } & 1 burst (VO) & 19 nurse (VO) & \\
\hline & cure $(\mathrm{SO})$ & & \\
\hline & pure (SO) & & \\
\hline & 4 birth (V) & & \\
\hline \multirow[t]{3}{*}{ key } & $1 \mathrm{Kay}(\mathrm{SO})$ & 12 hey $(O)$ & \\
\hline & clay (SR) & & \\
\hline & 7 hey (O) & & \\
\hline \multirow[t]{4}{*}{ lane } & 2 hang (SO) & $19 \operatorname{man}(\mathrm{SO})$ & 26 claim $(\mathrm{V})$ \\
\hline & & $\tan (\mathrm{SO})$ & $\operatorname{aim}(\mathrm{V})$ \\
\hline & & ban (SO) & fame (VO) \\
\hline & & fan $(\mathrm{SO})$ & \\
\hline \multirow[t]{2}{*}{ late } & 4 fake (VO) & & \\
\hline & 7 pate $(\mathrm{O})$ & & \\
\hline \multirow[t]{7}{*}{ lost } & 1 host $(\mathrm{O})$ & 12 host $(\mathrm{O})$ & 30 soft (VO) \\
\hline & just (SO) & 19 fart $(V)$ & \\
\hline & $2 \operatorname{moss}(\mathrm{VO})$ & $\operatorname{dart}(\mathrm{V})$ & \\
\hline & 3 locust (SO) & bust (SO) & \\
\hline & 4 fought $(\mathrm{V})$ & toss $(\mathrm{SO})$ & \\
\hline & 7 post $(\mathrm{O})$ & & \\
\hline & host $(\mathrm{O})$ & & \\
\hline \multirow[t]{8}{*}{ love } & 1 rove $(\mathrm{O})$ & 11 clove $(\mathrm{O})$ & \\
\hline & shovel (VO) & grove $(\mathrm{O})$ & \\
\hline & 3 cove $(O)$ & 13 jove $(\mathrm{O})$ & \\
\hline & wove $(\mathrm{O})$ & $17 \mathrm{SUV}(\mathrm{U})$ & \\
\hline & 5 cove $(O)$ & & \\
\hline & wove $(\mathrm{O})$ & & \\
\hline & 7 move $(\mathrm{O})$ & & \\
\hline & cove $(\mathrm{O})$ & & \\
\hline
\end{tabular}




\begin{tabular}{|c|c|c|c|}
\hline Targets & NCS & $\mathrm{CS}$ & Hearing \\
\hline \multirow[t]{2}{*}{ new } & 1 noon $(V)$ & 19 sew $(O)$ & \\
\hline & 3 sew $(O)$ & & \\
\hline \multirow[t]{6}{*}{ off } & 1 golf $(\mathrm{V})$ & 12 tough $(\mathrm{U})$ & 21 moth (VO) \\
\hline & of (SO) & huff (SR) & golf (VO) \\
\hline & 5 soft (VO) & 15 soft (VO) & \\
\hline & & loft (VO) & \\
\hline & & 18 soft (VO) & \\
\hline & & 19 golf (VO) & \\
\hline \multirow[t]{4}{*}{ one } & 1 once (VO) & 19 tone $(\mathrm{O})$ & \\
\hline & on (SO) & 17 tone $(\mathrm{O})$ & \\
\hline & 5 bon $(\mathrm{SO})$ & & \\
\hline & 7 lone $(\mathrm{O})$ & & \\
\hline \multirow[t]{7}{*}{ own } & 1 owe (VO) & 12 town $(\mathrm{O})$ & 21 rome $(\mathrm{V})$ \\
\hline & owl (SO) & 13 renown $(\mathrm{O})$ & 26 gone (U) \\
\hline & gown $(\mathrm{O})$ & 17 chrome (VO) & \\
\hline & $5 \operatorname{con}(\mathrm{U})$ & & \\
\hline & 7 down $(\mathrm{O})$ & & \\
\hline & gown $(\mathrm{O})$ & & \\
\hline & 8 owl (SO) & & \\
\hline \multirow[t]{2}{*}{ pail } & & $19 \operatorname{dial}(\mathrm{U})$ & 30 bell (SR) \\
\hline & & & fell (U) \\
\hline \multirow[t]{6}{*}{ peace } & 1 pea $(\mathrm{VO})$ & 17 belief (V) & 21 keys (V) \\
\hline & ace $(\mathrm{O})$ & leaf (VO) & tease $(\mathrm{VO})$ \\
\hline & ease (VO) & 19 fierce $(V)$ & 26 east (VO) \\
\hline & 2 feast (VO) & ease (VO) & \\
\hline & meet $(\mathrm{V})$ & tease (VO) & \\
\hline & 4 tense $(\mathrm{U})$ & yeast (VO) & \\
\hline \multirow[t]{3}{*}{ phone } & 2 phony (VO) & 13 renown $(\mathrm{U})$ & 21 rome (VO) \\
\hline & foe (VO) & & 26 on $(\mathrm{SO})$ \\
\hline & & & gone $(\mathrm{O})$ \\
\hline \multirow[t]{12}{*}{ please } & 1 pledge $(\mathrm{U})$ & 11 peace $(\mathrm{VO})$ & 21 cease $(\mathrm{VO})$ \\
\hline & $2 \operatorname{need}(\mathrm{V})$ & fleece $(\mathrm{V})$ & \\
\hline & heed (V) & cleanse (SO) & \\
\hline & lead (VO) & 12 lease (VO) & \\
\hline & seed $(\mathrm{V})$ & 13 grease $(\mathrm{VO})$ & \\
\hline & weed $(\mathrm{V})$ & 17 lease (VO) & \\
\hline & pied $(\mathrm{U}) 18$ & crease (VO) & \\
\hline & cease $(\mathrm{VO})$ & lease (VO) & \\
\hline & $\operatorname{read}(\mathrm{VO})$ & cease $(\mathrm{VO})$ & \\
\hline & 5 deceased $(\mathrm{VO})$ & 19 geese $(\mathrm{V})$ & \\
\hline & 7 lease (VO) & cease $(\mathrm{VO})$ & \\
\hline & cease $(\mathrm{VO})$ & 20 lease (VO) & \\
\hline \multirow[t]{2}{*}{ pour } & 1 tour $(\mathrm{O})$ & 12 tour $(\mathrm{O})$ & 22 tour $(\mathrm{O})$ \\
\hline & our $(\mathrm{O})$ & 13 boor $(\mathrm{O})$ & 24 lure (SO) \\
\hline
\end{tabular}




\begin{tabular}{|c|c|c|c|}
\hline Targets & NCS & CS & Hearing \\
\hline & flour $(\mathrm{O})$ & 16 tour $(\mathrm{O})$ & 30 sure $(\mathrm{SO})$ \\
\hline & 5 flour $(\mathrm{O})$ & 19 tour $(\mathrm{O})$ & \\
\hline & 6 tour $(\mathrm{O})$ & sour $(\mathrm{O})$ & \\
\hline \multirow[t]{2}{*}{ rain } & $4 \operatorname{ten}(\mathrm{U})$ & $12 \operatorname{ran}(\mathrm{SO})$ & \\
\hline & 5 sang $(\mathrm{U})$ & $\begin{array}{l}19 \text { faint }(\mathrm{VO}) \\
\text { whail }(\mathrm{VO})\end{array}$ & \\
\hline red & $1 \mathrm{GED}(\mathrm{O})$ & $\begin{array}{c}19 \text { mead }(\mathrm{U}) \\
\text { mend }(\mathrm{VO}) \\
\operatorname{den}(\mathrm{VO})\end{array}$ & 30 kid (U) \\
\hline \multirow[t]{3}{*}{ rule } & 1 joules (VO) & 17 pull (SO) & \\
\hline & 8 ruler $(\mathrm{VO})$ & dull (SO) & \\
\hline & & 19 wool (SR) & \\
\hline \multirow[t]{5}{*}{ said } & 1 aid $(\mathrm{O})$ & $12 \mathrm{sad}(\mathrm{SO})$ & 30 kid (SO) \\
\hline & sat (SO) & 19 mead $(U)$ & \\
\hline & $\operatorname{sad}(\mathrm{SO})$ & laid $(\mathrm{O})$ & \\
\hline & 4 say $(\mathrm{SO})$ & paid $(\mathrm{O})$ & \\
\hline & 6 plaid $(\mathrm{O})$ & & \\
\hline \multicolumn{4}{|l|}{ sale } \\
\hline \multirow[t]{2}{*}{ school } & 3 wool $(\mathrm{O})$ & 15 wool (O) & 28 pull (U) \\
\hline & & 18 whole $(\mathrm{SO})$ & \\
\hline see & 5 easy $(\mathrm{V})$ & & \\
\hline \multirow[t]{2}{*}{ shirt } & 1 sheet $(\mathrm{SO})$ & & \\
\hline & $\operatorname{church}(\mathrm{V})$ & & \\
\hline \multirow[t]{3}{*}{ shoe } & 1 hoe $(\mathrm{O})$ & & \\
\hline & 5 foo $(\mathrm{V})$ & & \\
\hline & 8 hoe $(\mathrm{O})$ & & \\
\hline \multirow[t]{3}{*}{ should } & & 17 flood (U) & \\
\hline & & blood (U) & \\
\hline & & lewd (U) & \\
\hline \multirow[t]{5}{*}{ socks } & 1 shock (VO) & 17 poxs (VO) & $26 \operatorname{coxs}(\mathrm{VO})$ \\
\hline & $\operatorname{cock}(\mathrm{VO})$ & & \\
\hline & 4 lock (VO) & & \\
\hline & 5 oxs (VO) & & \\
\hline & 8 sock (VO) & & \\
\hline \multirow[t]{4}{*}{ speech } & 1 pinch $(\mathrm{SO})$ & 17 leash $(\mathrm{V})$ & \\
\hline & & cleat $(\mathrm{V})$ & \\
\hline & & $19 \operatorname{search}(\mathrm{SO})$ & \\
\hline & & 20 quiche (V) & \\
\hline \multirow[t]{3}{*}{ steal } & & 12 stale $(\mathrm{SO})$ & 21 veil (SO) \\
\hline & & & 26 will (U) \\
\hline & & & gill (SR) \\
\hline \multirow[t]{2}{*}{ tacks } & 1 sack (VO) & 12 hack (VO) & \\
\hline & pack (VO) & 19 mack (VO) & \\
\hline $\operatorname{tax}$ & 1 taxi (VO) & 19 whack (VO) & \\
\hline
\end{tabular}




\begin{tabular}{|c|c|c|c|}
\hline Targets & NCS & CS & Hearing \\
\hline & $\begin{array}{r}2 \text { sack (VO) } \\
\text { hack (VO) } \\
\text { pact (VO) }\end{array}$ & hack (VO) & \\
\hline tea & & & 21 brei (V) \\
\hline thief & $\begin{array}{c}1 \text { this }(\mathrm{SO}) \\
\text { thing }(\mathrm{V}) \\
2 \text { sheath }(\mathrm{V})\end{array}$ & $\begin{array}{l}17 \text { cleave }(\mathrm{V}) \\
\text { niece }(\mathrm{VO})\end{array}$ & $\begin{array}{l}26 \text { left }(\mathrm{SO}) \\
27 \text { bequeath }(\mathrm{V}) \\
\text { teeth }(\mathrm{V}) \\
\text { beneath }(\mathrm{V})\end{array}$ \\
\hline tie & $\begin{array}{l}1 \operatorname{tired}(\mathrm{VO}) \\
\operatorname{tin}(\mathrm{SO}) \\
6 \text { time }(\mathrm{VO}) \\
8 \text { kite }(\mathrm{VO})\end{array}$ & & \\
\hline vote & $\begin{array}{c}1 \text { forty (VO) } \\
\text { fool (U) } \\
4 \text { oak (V) }\end{array}$ & $\begin{array}{c}17 \text { sloat }(\mathrm{VO}) \\
19 \operatorname{dot}(\mathrm{SO}) \\
\operatorname{hoax}(\mathrm{V}) \\
\operatorname{loot}(\mathrm{SO})\end{array}$ & $29 \cot (\mathrm{SO})$ \\
\hline warm & $\begin{array}{l}1 \text { carmel }(\mathrm{SO}) \\
\text { farm }(\mathrm{O})\end{array}$ & $\begin{array}{l}11 \text { farm }(\mathrm{O}) \\
12 \operatorname{harm}(\mathrm{O}) \\
14 \operatorname{charm}(\mathrm{O})\end{array}$ & $\begin{array}{l}23 \operatorname{torn}(\mathrm{V}) \\
\quad \operatorname{mourn}(\mathrm{V}) \\
28 \operatorname{farm}(\mathrm{O})\end{array}$ \\
\hline & $\begin{array}{l}2 \text { farm }(\mathrm{O}) \\
\text { warn }(\mathrm{VO}) \\
4 \text { worm }(\mathrm{SO}) \\
5 \text { farm }(\mathrm{VO}) \\
9 \text { warn }(\mathrm{VO})\end{array}$ & $\begin{array}{c}\text { alarm }(\mathrm{O}) \\
\text { farm }(\mathrm{O}) \\
17 \text { forlorn }(\mathrm{V}) \\
\operatorname{adorn}(\mathrm{V}) \\
\operatorname{lorn}(\mathrm{V}) \\
\text { swarn }(\mathrm{VO}) \\
19 \text { farm }(\mathrm{O}) \\
\operatorname{harm}(\mathrm{O}) \\
20 \text { farm }(\mathrm{O})\end{array}$ & \\
\hline weigh & $\begin{array}{c}1 \text { we }(\mathrm{SO}) \\
\text { wright }(\mathrm{SO}) \\
\text { Wes }(\mathrm{SO}) \\
5 \text { freight }(\mathrm{VO})\end{array}$ & $\begin{array}{l}12 \text { wait }(\mathrm{V}) \\
17 \text { ale }(\mathrm{V})\end{array}$ & \\
\hline won & $\begin{array}{l}1 \text { want }(\mathrm{V}) \\
\text { would }(\mathrm{U}) \\
\text { wore }(\mathrm{SO}) \\
5 \text { mon }(\mathrm{VO})\end{array}$ & $\begin{array}{c}16 \text { bonbon }(\mathrm{O}) \\
\text { con }(\mathrm{O}) \\
\text { Todd }(\mathrm{O}) \\
\text { Mon }(\mathrm{VO}) \\
17 \text { con }(\mathrm{O}) \\
19 \text { gone }(\mathrm{SO})\end{array}$ & 26 bond $(\mathrm{SO})$ \\
\hline wood & $\begin{array}{l}1 \operatorname{won}(\mathrm{SO}) \\
4 \operatorname{word}(\mathrm{V}) \\
7 \operatorname{mood}(\mathrm{O})\end{array}$ & $\begin{array}{c}14 \text { food }(\mathrm{O}) \\
\operatorname{mood}(\mathrm{O}) \\
17 \text { flood }(\mathrm{O}) \\
\operatorname{blood}(\mathrm{O}) \\
\text { lewd }(\mathrm{U})\end{array}$ & \\
\hline
\end{tabular}

V, vowel; VO, vowel orthographic; $\mathrm{O}$, orthographic; SO, some orthographic; SR, speech related; $\mathrm{U}$, unclassifiable. Numerals refer to the identification numbers of participants (1-10 NCS, 11-20 CS, 21-30 hearing). 


\section{Notes}

1. For the purpose of clarity, the 54 words presented to study participants are referred to as targets. The specific words written by the study participants are referred to as responses. Targets can be described as being either O-P or I-O-P. A target is considered $\mathrm{O}-\mathrm{P}$ if the spelling of its rime (the rhyming element of the word) is always pronounced the same way. An example of an O-P target is blue. The rime -ue is consistently pronounced /oo/. A target is considered I-O-P if the spelling of its rime is not always pronounced the same way. An example of an I-O-P target is bear. The rime-ear can be pronounced as in bear or /ir/ as in fear. These distinctions have nothing to do with participants' responses. Correct responses (i.e., responses that rhyme with their targets) can be described as being either orthographically similar (O-S) or orthographically dissimilar (O-D) to their targets. A correct response might be orthographically similar to an O-P target (blue/true), orthographically similar to an I-O-P target (bear/pear), orthographically dissimilar to an OP target (blue/flew), or orthographically dissimilar to an I-O-P target (bear/hair). Error responses are separated into six error categories.

2. An ANCOVA has also been run with group as the betweensubjects factor, consistency as the within-subjects factor, and SAT scores as covariate. The effects of consistency and group were significant, whereas the interaction between group and consistency was not. The effect of SAT was not significant; therefore the results of the ANOVA were reported here.

\section{References}

Alegria, J., Charlier, B., \& Mattys, S. (1999). The role of lipreading and Cued Speech in the processing of phonological information in French-educated deaf children. European Journal of Cognitive Psychology, 11, 451-452.

Bradley, L. (1988). Rhyme recognition, reading, and spelling in young children. In R. Masland \& M. Masland (Eds.), Preschool prevention of reading failure (pp. 143-162). Parkton, MD: York Press.

Bradley, L., \& Bryant, P. (1983). Categorizing sounds and learning to read: A causal connection. Nature, 301, 419-421.

Bradley, L., \& Bryant, P. (1985). Rhyme and reason in reading and spelling (IARLD Monographs, No. 1). Ann Arbor: University of Michigan Press.

Bryant, P., MacLean, M., \& Bradley, L. (1990). Rhyme, language, and children's reading. Applied Linguistics, 11, 237-252.

Bryant, P. MacLean, M., Bradley, L., \& Crossland, J. (1990). Rhyme and alliteration, phoneme detection, and learning to reading. Developmental Psychology, 26, 429-438.

Campbell, R., \& Wright, H (1988). Deafness, spelling, and rhyme: How spelling supports written words and picture rhyming skills in deaf participants. Quarterly Fournal in Experimental Psychology, 40, 71-778.

Cardoso-Martins, C. (1994). Rhyme perception: Global or analytical? Quarterly fournal in Experimental Psychology, 57, 26-41.

Charlier, B., \& Leybaert, J. (2000). The rhyming skills of deaf children educated with phonetically augmented lipreading. Quarterly Fournal of Experimental Psychology, 53A, 349-375.
Cornett, O. (1994). Adapting Cued Speech to additional languages. Cued Speech Fournal, 5, 19-36.

Cornett, R., \& Daisey, M. (1992). The Cued Speech resource book for parents of deaf children. Raleigh, NC: National Cued Speech Corporation.

Dodd, D., \& Hermelin, B. (1977). Phonological coding by the prelinguistically deaf. Perception and Psychophysics, 21, 413-417.

Ellis, N., \& Large. B. (1987). The development of reading: As you seek so shall you find. British Journal of Psychology, 78, 1-28.

Gates, A., \& MacGinitie, W. (1969). Gates MacGinitie Reading Tests, Survey F, Form 2, Boston: Houghton Mifflin.

Hage, C., Alegria, J., \& Perier, O. (1990). Cued Speech and language acquisition: The case of grammatical gender morphophonology. In D. Martin (Ed.), Advances in cognition, education, and deafness. Washington, DC: Gallaudet University Press.

Hanson, V., \& Fowler, C. (1987). Phonological coding in word reading: Evidence from hearing and deaf readers. Memory and Cognition, 15, 199-207.

Hanson, V., \& McGarr, N. (1989). Rhyme generation in deaf adults. Fournal of Speech and Hearing Research, 32, 2-11.

Harris, M., \& Beech, J. (1995). Reading development in prelingually deaf children. In K. Nelson \& Z. Reger (Eds.), Children's language. Hillsdale, NJ: Lawrence Erlbaum Associates.

International Phonetic Association. (1996). Reproduction of the International Phonetic Alphabet. Retrieved June 2, 2003, from International Phonetic Association Web site: http:// www2.arts.gla.ac.uk/IPA/fullchart.html

Kipila, B., \& Williams-Scott, B. (1990). Cued Speech. In H. Bornstein (Ed.), Manual communication: Implications for education (pp. 139-150). Washington DC: Gallaudet University Press.

LaSasso, C. (1987). What parents need to know about reading levels of hearing impaired students. American Annals of the Deaf, 132, 218-220.

LaSasso, C., \& Metzger, M. (1998). An alternate route for preparing deaf children for BiBi programs: The home language as L1 and Cued Speech for conveying traditionally-spoken languages. Fournal of Deaf Studies and Deaf Education, 3, 264289.

Lenel, J., \& Cantor, J. (1981). Rhyme recognition and phonemic perception in young children. Fournal of Psycholinguistic Research, 10, 57-67.

Leybaert, J. (1993). Reading in the deaf: The roles of phonological codes. In M. Marschark \& D. Clark (Eds.), Psychological perspectives on Deafness (pp. 269-311). Hillsdale: Lawrence Erlbaum Associates.

Leybaert, J. (2000). Phonology acquired through the eyes and spelling in deaf children. Fournal of Experimental Child Psychology, 75, 291-318.

Lundberg, I., Olofsson, A., \& Wall, S. (1980). Reading and spelling skills in the first school years, predicted from phonemic awareness skills in kindergarten. Scandinavian fournal of Psychiatry, 21, 159-173.

MacLean, M., Bryant, P., \& Bradley, L. (1987). Rhymes, nursery rhymes, and reading in early childhood. Merrill-Palmer Quarterly, 33, 25-282.

Morais, J., Bertelson, P., Cary, L., \& Alegrica, J. (1986). Literacy training and speech segmentation. Cognition, 24, 45-64. 
Nicholls, G., \& Ling, D. (1982). Cued Speech and the reception of spoken language. Fournal of Speech and Hearing Research, 25, 262-269.

Parasnis, I. (1996). Relationship between rhyme generation and English skills in profoundly deaf readers. Paper presented at the 1996 annual meeting of the American Educational Research Association. New York, NY.

Perier, O., Charlier, B., Hage, C., \& Alegria, J. (1988). Evaluation of the effects of prolonged Cued Speech practice upon the reception of spoken language. In I. Taylor (Ed.), The education of the deaf: Current perspectives, Vol 1. London: Croom Helm.

Read, C. (1978). Children's awareness of language, with an emphasis on sound systems. In A. Sinclair, R. Jarvella, \& W. Levelt (Eds.), The child's conception of language (pp. 65-92). New York: Springer-Verlag.

Random House College Dictionary (1988). Random House, Inc., New York.

Slobin, C. (1978). A case study of early language awareness. In A. Sinclair, R. Jarvella, \& W. Levelt (Eds.), The child's conception of language (pp. 45-54). New York: Spring-Verlag.
Stanford Achievement Test (9th Edition) Norms Booklet (1996). New York: The Psychological Corporation: Harcourt Brace Javanovich.

Tammasaeng, M. (1985). The effects of Cued Speech upon tonal perception of the Thai language by hearing-impaired children. Unpublished doctoral dissertation, Gallaudet University, Washington, DC.

Webster, P., \& Plante, A. (1995). Productive phonology and phonological awareness in preschool children. Applied Psycholinguistics, 16, 43-57.

Ziegler, J., Stone, G., \& Jacobs, A. (1997). What is the pronunciation for _OUGH and the spelling for / $\mathrm{u} /$ ? A database for computing feedforward and feedback consistency in English. Behavior Research Methods, Instruments, and Computers, 29, 660-678.

Received October 10, 2001; revisions received March 4, 2002; accepted March 14, 2002 